\title{
RESISTÊNCIA ANTIMICROBIANA DE Salmonella SPP., Staphylococcus aureus E Escherichia coli ISOLADOS DE CARCAÇAS DE FRANGOS: RESISTÊNCIA A ANTIBIÓTICOS E ÓLEOS ESSENCIAIS
}

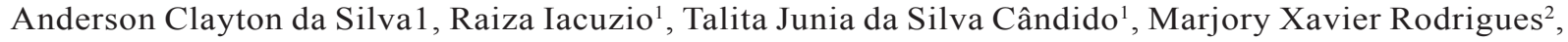 \\ Nathalia Cristina Cirone Silva $1^{*}$
}

\begin{abstract}
RESUMO - Patógenos alimentares resistentes a antimicrobianos são uma preocupação de saúde pública ao redor do mundo. A resistência a antibióticos está sendo cada vez mais comum entre cepas isoladas de alimentos, assim, alternativas aos antibióticos estão sendo propostas. Óleos essenciais vêm sendo estudados para a aplicação na indústria de alimentos por possuírem atividade antimicrobiana e antioxidante. Desse modo, objetivou-se com este trabalho identificar o perfil de resistência antimicrobiana de Salmonella spp., Staphylococcus aureus e Escherichia coli isolados de frangos empregando diferentes antibióticos e os óleos essenciais de alecrim (Rosmarinus officinalis), capim-limão (Cymbopogon citratus) e pimenta preta (Piper nigrum). Métodos convencionais de microbiologia foram utilizados para a obtenção dos isolados bacterianos, método de disco-difusão foi empregado para identificar a resistência a antibióticos, ensaios de microplaca de resazurina foram realizados para identificar a concentração inibitória mínima (CIM) de óleos essenciais, e então a concentração bactericida mínima (CBM) foi estabelecida a partir da CIM desenvolvendo a técnica da micro gota. Frequência, média, desvio-padrão, análise de variância e teste de Tukey foram calculados para a análise dos resultados. Destacam-se entre os resultados obtidos a frequência de carcaças de frangos contaminadas por Escherichia coli, Staphylococcus aureus e Salmonella spp., 70\%, 40\%, e 25\%, respectivamente, sendo que a resistência dos isolados a um ou mais antibióticos foi detectada em $90,9 \%, 66,6 \%$ e 55,6\% dos isolados de E. coli, Salmonella spp. e S. aureus, respectivamente. Em adição, a multirresistência foi amplamente identificada. Quanto aos resultados obtidos para as análises de CIM dos óleos essenciais analisados, foi possível observar um melhor desempenho dos óleos essenciais de alecrim e capim limão, respectivamente, contudo sem diferença significativa entre as amostras. Os resultados reforçam a preocupação com a disseminação de cepas resistentes a antimicrobianos e a necessidade do desenvolvimento ou melhoramento de alternativas ao uso de antibióticos.
\end{abstract}

Palavras chave: antimicrobiano, antibiograma, Cymbopogon citratus, patógenos alimentares, Piper nigrum, Rosmarinus officinalis.

\section{ANTIMICROBIAL RESISTANCE OF Salmonella SPP., Staphylococcus aureus AND Escherichia coli ISOLATED FROM CHICKEN CARCASSES: RESISTANCE TO ANTIBIOTICS AND ESSENTIAL OILS}

\begin{abstract}
Foodborne antimicrobial resistant microorganisms are a concern to public health worldwide. Antibiotic resistance has been frequently found in strains isolated from food; thus, alternatives to antibiotics are being proposed. Essential oils have been studied in order to apply in food industry because they have antimicrobial and antioxidant properties. Thereby, this work had as aim to identify the antimicrobial profile of Salmonella spp., Staphylococcus aureus and Escherichia coli isolated from chicken using several antibiotics and essential oils of rosemary (Rosmarinus officinalis), lemongrass (Cymbopogon citratus) and black pepper (Piper nigrum). Conventional microbiological methods were applied to obtain bacteria isolates, diffusion
\end{abstract}

\footnotetext{
${ }^{1}$ Universidade Estadual de Campinas - Cidade Universitária Zeferino Vaz, Campinas, São Paulo - Brasil

${ }^{2}$ Department of Population Medicine and Diagnostic Sciences, Cornell University College of Veterinary Medicine, Ithaca, NY 1 Fontes Financiadoras: CNPQ, CAPES, FAEPEX, PRP/UNICAMP

*ncirone@unicamp.br
} 
agar method was used to identify the antibiotic resistance, resazurin microplate assays were carried out to identify minimum inhibitory concentration (MIC); following the minimum bactericidal concentration (MBC) was found from MIC using drop plate method. Frequency, mean, standard error mean, variance analysis and Tukey test were calculated to results analysis. The frequency obtained to chicken carcasses contaminated was highlighted, Escherichia coli, Staphylococcus aureus and Salmonella spp. were identified in 70\%, 40\%, and $25 \%$ of carcasses, respectively; the resistance to one or more antibiotic was detected in $90.9 \%, 66.6 \%$ and 55.6\% of E. coli, Salmonella spp. and S. aureus isolates, respectively. In addition, the multiresistance was widely identified. Among results from essential oils assays is emphasized rosemary performance when compared to other oils; however, for MIC there was no significant difference to essential oils of rosemary and lemongrass. The results reinforce the concern with antimicrobial resistant bacteria dissemination and with the necessity of development and improvements of alternatives to antibiotic use.

Keywords: antimicrobial, antibiogram, Cymbopogon citratus, foodborne pathogens, Piper nigrum, Rosmarinus officinalis.

\section{INTRODUÇÃO}

Staphylococcus aureus, Salmonella e Escherichia coli são importantes patógenos alimentares (Wang et al., 2013; Jong et al., 2014; Zhang et al., 2016), e estão dentre os maiores causadores de surtos no Brasil (Ministério da Saúde, 2016). Carnes de ave in natura, processados e miúdos representaram $1,4 \%$ dos surtos notificados no Brasil entre 2007 e 2016, vale ressaltar que em $66,8 \%$ dos casos os alimentos não foram identificados (Ministério da Saúde, 2016), sendo ainda este fato um transtorno para estudos epidemiológicos no país. A prevenção e o controle de doenças transmitidas por alimentos vêm sendo citados como um desafio e a resistência antimicrobiana entre patógenos alimentares como um problema crescente (Seventer \& Hamer, 2017). Yap et al. (2014) mencionam a resistência bacteriana como um dos mais significantes desafios para a saúde humana. A resistência a antibióticos dentro da produção de alimentos é uma preocupação para a saúde pública, é claro que antibióticos usados em tratamento de humanos e animais agem como uma importante pressão seletiva para o surgimento e persistência de cepas resistentes (Gebreyes et al., 2017). Alternativas ao uso de antibióticos têm sido propostas nos últimos anos, algumas abordagens incluem probióticos, prebióticos, simbióticos, e produtos à base de plantas (Gebreyes et al., 2017).

Óleos essenciais (Oes) têm recebido muita atenção nas últimas décadas devido à atividade antimicrobiana que apresentam (Bassanetti et al., 2017). Óleos essenciais, ou terpenos, são metabólitos secundários baseados em uma estrutura de isopreno, são compostos voláteis que fornecem a essência da planta, sendo responsáveis pelo flavor e aroma de especiarias (Hintz et al., 2015).
Muitos Oes têm demonstrado eficiência contra patógenos alimentares e microrganismos deteriorantes (Bassanetti et al., 2017). Pesquisas avaliando a eficiência de Oes contra diferentes patógenos têm sido desenvolvidas, por exemplo, com Oes de mostarda (Clemente et al., 2016), canela (Pesavento et al., 2015; Clemente et al., 2016), frutas cítricas (Settani et al., 2012), alecrim, orégano, tomilho, sálvia (Pesavento et al., 2015) e pimenta (Dannenberg et al., 2017). Portanto, produtos derivados de plantas como agentes antimicrobianos são alvo de pesquisas visando utilizá-los para a conservação de alimentos e controle de patógenos transmitidos por alimentos (Hintz et al., 2015).

Considerando o exposto objetivou-se com este trabalho identificar o perfil de resistência antimicrobiana de Salmonella spp., Staphylococcus aureus e Escherichia coli isolados de frangos, obtidos em pontos de venda ao consumidor, empregando diferentes antibióticos e óleos essenciais de alecrim (Rosmarinus officinalis), capim-limão (Cymbopogon citratus) e pimenta preta (Piper nigrum).

\section{MATERIAL E MÉTODOS}

\section{Coleta e preparo de amostras}

Carcaças de frango congeladas foram obtidas aleatoriamente em supermercados da cidade de Campinas (São Paulo, Brasil), provenientes de diferentes frigoríficos. No total, 20 carcaças foram coletadas e transportadas em caixas isotérmicas até o laboratório de toxinas microbianas da Universidade Estadual de Campinas (UNICAMP) para o desenvolvimento das análises planejadas. Após a recepção das amostras, as mesmas foram preparadas a fim de obter a diluição decimal 
necessária para as análises microbiológicas que serão descritas a seguir. Porções de coxas, sobrecoxas, asas e pele foram cortadas e misturadas assepticamente, foram pesados $25 \mathrm{~g}$ de amostra sendo esta porção homogeneizada em $225 \mathrm{~mL}$ de água peptonada $0,1 \%$ $(\mathrm{p} / \mathrm{v})\left(\right.$ Acumedia $\left.^{\circledR}\right)$ e a partir deste homogeneizado $\left(10^{-}\right.$ 1) foram realizadas diluições decimais em $9 \mathrm{~mL}$ de água peptonada $0,1 \%(\mathrm{p} / \mathrm{v})$ até a obtenção da diluição $10^{-}$ ${ }^{3}$ (Silva et al., 2010).

\section{Identificação de Escherichia coli}

A identificação de E. coli foi realizada a partir da análise de coliformes termotolerantes, sendo utilizada a técnica do Número Mais Provável (NMP) em séries de três tubos de acordo com Instrução Normativa $\mathrm{N}^{\circ}$ 62, de 26 de agosto de 2003 (Brasil, 2003a). Teste presuntivo, em Caldo Lauril Sulfato Triptose (LST) (Merck ${ }^{\mathrm{TM}}$, São Paulo - SP) e incubação a $35^{\circ} \mathrm{C}$ por 24 a 48 horas, e confirmativo, em caldo Escherichia coli (EC) (Oxoid ${ }^{\mathrm{TM}}$, São Paulo - SP) e incubação a $45^{\circ} \mathrm{C}$ por 24 a 48 horas, foram empregados. Os tubos com EC que apresentaram turbidez e formação de gás foram selecionados, coletou-se então uma alçada do cultivo e fez-se estriamento descontínuo em ágar Eosina Azul de Metileno (EMB) (Oxoid ${ }^{\mathrm{TM}}$, São Paulo - SP). As colônias típicas de $E$. coli foram submetidas aos testes bioquímicos vermelho de metila, Voges-Proskauer (Kasvi, São José dos Pinhais - PR), produção de indol (Difco ${ }^{\mathrm{TM}}$ ) e citrato de Simmons (BD ${ }^{\mathrm{TM}}$, São Paulo - SP) (Silva et al., 2010).

\section{Identificação de Salmonella spp.}

Para a pesquisa de Salmonella spp. procedeuse a etapa de pré-enriquecimento em água peptonada, com incubação a $37^{\circ} \mathrm{C}$ por 18 horas. A seguir, na etapa de enriquecimento, transferiu-se alíquotas de $1 \mathrm{~mL}$ para o caldo tetrationado (Oxoid ${ }^{\mathrm{TM}}$, São Paulo - SP) e 0,1 $\mathrm{mL}$ para o caldo Rappaport Vassiliadis (Oxoid ${ }^{\mathrm{TM}}$, São Paulo - SP) os quais foram incubados a $37^{\circ} \mathrm{C}$ por 24 horas. Uma alçada dos caldos de enriquecimento foi estriada em placas contendo ágar bismuto sulfito (BSA) $\left(\mathrm{BD}^{\mathrm{TM}}\right.$, São Paulo - SP), ágar Salmonella Shigella (SS) (Oxoid ${ }^{\mathrm{IM}}$, São Paulo - SP) e Ágar Xilose-Lisina Deoxicolato (XLD) (Oxoid ${ }^{\mathrm{TM}}$, São Paulo - SP), e as placas foram incubadas a $37^{\circ} \mathrm{C}$ por 24 horas. Colônias suspeitas foram transferidas para tubos contendo ágar nutriente, e realizou-se incubação a $37^{\circ} \mathrm{C}$ por 24 horas. As colônias suspeitas foram submetidas aos testes de reação em ágar tríplice açúcar ferro (TSI) (Merck ${ }^{\mathrm{TM}}$, São Paulo
- SP), descarboxilação de lisina utilizando o ágar lisina ferro (LIA) (Sinergia Científica ${ }^{\circledR}$, Campinas - SP), desaminação da fenilalanina em ágar fenilalanina (BD TM, São Paulo - SP), vermelho de metila, Voges-Proskauer (Kasvi, São José dos Pinhais - PR), produção de indol (Difco ${ }^{\mathrm{TM}}$, São Paulo - SP) e citrato de Simmons (BD ${ }^{\mathrm{TM}}$, São Paulo - SP) e por fim a Reação sorológica frente ao anti-soro polivalente (Probac ${ }^{\circledR}$ Brasil). As análises foram realizadas seguindo instruções para a detecção de Salmonella spp. conforme (Silva et al., 2010).

\section{Identificação de Staphylococcus aureus}

Com base na metodologia descrita na Instrução Normativa $\mathrm{N}^{\mathrm{o}} 62$, de 26 de agosto de 2003 (Brasil, 2003a), realizou-se a identificação de $S$. aureus. Em placas contendo ágar Baird Parker (BPA) (Acumedia ${ }^{\circledR}$, Indaiatuba - SP) e solução de gema de ovo com telurito de potássio foi disposto um volume de $0,1 \mathrm{~mL}$ cada diluição seriada preparada previamente, e fez-se o espalhamento em superfície utilizando alça de Drigalski. As placas de BPA foram incubadas a $35^{\circ} \mathrm{C}$ por 30 a 48 horas, após a incubação foram selecionadas três colônias típicas por placa, as quais foram repicadas posteriormente em ágar Brain Heart Infusion (BHI) (Acumedia ${ }^{\circledR}$ Indaiatuba - SP) inclinado $\left(35^{\circ} \mathrm{C}\right.$ por 24 horas $)$ para as análises bioquímicas. Realizou-se com os isolados obtidos coloração de Gram, teste de produção de catalase e por fim teste de produção de coagulase.

\section{Identificação do fenótipo de resistência a antibióticos}

Para a identificação de resistência a antibióticos foi realizado o método de disco-difusão conforme Clinical and Laboratory Standars Institute (CLSI, 2015). Os isolados (E. coli, Salmonella e S. aureus) foram repicados em caldo BHI (Acumedia ${ }^{\circledR}$, Indaiatuba - SP) e após 24 horas a $35^{\circ} \mathrm{C}$ os cultivos foram padronizados utilizando a escala McFarland para a obtenção de suspensões bacterianas correspondendo a 0,5 na escala, aproximadamente $10^{8} \mathrm{UFC} / \mathrm{mL}$. As suspensões foram semeadas em ágar Mueller-Hinton (Kasvi São José dos Pinhais - PR) e discos impregnados com antibióticos (Laborclin, Pinhais - PR) foram dispostos sobre o meio. As placas foram incubadas a $35^{\circ} \mathrm{C}$ por 18 horas. Após este período os halos foram medidos e interpretados segundo a CLSI (2015), os quais foram apresentados de acordo com a frequência (\%) identificada para resistentes, resistentes intermediários e susceptíveis a antibióticos. 
Para a identificação de resistência a antibióticos de E. coli e Salmonella spp. foram utilizados discos impregnados com ampicilina $(10 \mu \mathrm{g})$, amoxilicina-ácido clavulânico $(20 / 10 \mu \mathrm{g})$, cefoxitina $(30 \mu \mathrm{g})$, aztreonam $(30 \mu \mathrm{g})$, imipenem $(10 \mu \mathrm{g})$, gentamicina $(10 \mu \mathrm{g})$, tobramicina $(10 \mu \mathrm{g})$, tetraciclina $(30 \mu \mathrm{g})$ e cloranfenicol $(30 \mu \mathrm{g})$. Para análise da resistência de $S$. aureus foram utilizados discos impregnados com penicilina (10 ìg), oxacilina (1 ̀̀g), cefoxitina (30 ìg), gentamicina (10 ìg), tobramicina (10 ìg), eritromicina (15 ìg), tetraciclina (30 ig), clindamicina (2 ìg) e cloranfenicol (30 ìg).

\section{Identificação da Concentração Inibitória Mínima (CIM)}

A CIM foi determinada para os óleos essenciais de alecrim (Rosmarinus officinalis), capim-limão (Cymbopogon citratus) e pimenta preta (Piper nigrum) (Givaudan, São Paulo, Brasil) frente a três cepas de cada patógeno estudado. No total, nove cepas aleatórias foram inoculadas em caldo BHI, seguindo para incubação a $37^{\circ} \mathrm{C}$ por 24 horas. As suspensões bacterianas foram padronizadas conforme mencionado anteriormente para a utilização de suspensões com aproximadamente $10^{8} \mathrm{UFC} /$ $\mathrm{mL}$, posteriormente foram diluídas até a concentração de $10^{5} \mathrm{UFC} / \mathrm{mL}$.

Foram utilizadas placas de 96 poços, contendo $200 \mu \mathrm{L}$ de caldo triptona soja (TSB) (BD ${ }^{\mathrm{TM}}$, São Paulo - SP) adicionado de $0,5 \%$ de Tween 80 em cada poço. Nos poços da primeira coluna, foram adicionados 360 $\mu \mathrm{L}$ de caldo TSB adicionado de Tween 80 homogeneizado com $40 \mu \mathrm{L}$ de óleo essencial ou $40 \mu \mathrm{L}$ de solução estoque do antibiótico comercial oxacilina (SigmaAldrich ${ }^{\circledR}$, São Paulo - SP) na concentração de $0,5 \mathrm{mg} / \mathrm{mL}$. Posteriormente, foi realizada diluição seriada a partir da transferência de $200 \mu 1$ de mistura do primeiro poço da linha para o segundo e assim sucessivamente. Por fim, foram inoculados $2 \mu \mathrm{L}$ de suspensão bacteriana, resultando em concentração final de $10^{3} \mathrm{UFC} / \mathrm{mL}$ por poço. As placas foram submetidas à incubação a $37^{\circ} \mathrm{C}$ por 24 horas. Após incubação, foram adicionados 50 $\mu \mathrm{L}$ de solução de resazurina $0,01 \%$ e após cinco minutos verificou-se a ocorrência de coloração indicativa do crescimento microbiano. O poço com menor concentração do agente antimicrobiano que permanece com coloração azul apresenta a concentração inibitória mínima enquanto a viragem para cor rosa indica crescimento bacteriano (Perazzo, 2012). O procedimento foi realizado em triplicata. Para cálculo da média, desvio-padrão, análise de variância (ANOVA) e teste de médias (método de Tukey, Pd'0,05) foi utilizado o software Sisvar, versão: 5.6, build: 86 (Lavras, MG, Brasil).

\section{Identificação da Concentração Bactericida Mínima (CBM)}

Para realização da análise da CBM foram retirados $10 \mu \mathrm{L}$ do poço referente ao CIM e de três poços anteriores, os quais foram depositados em placas com ágar nutriente (Oxoid $^{\mathrm{TM}}$, São Paulo- PR) por técnica de micro gota, conforme descrito por Knezevic (et al., 2016). As placas foram submetidas à incubação a $37^{\circ} \mathrm{C}$ por 24 horas. Após a incubação, seções nas quais não houve crescimento indicaram atividade bactericida, enquanto seções com crescimento positivo indicam atividade bacteriostática do composto analisado para a concentração relacionada (Knezevic et al., 2016). Os resultados da CBM são apresentados para cada cepa testada.

\section{RESULTADOS E DISCUSSÃO}

Os dados do isolamento de patógenos alimentares de carcaças de frango estão apresentados na Tabela 1 .

A frequência encontrada de Salmonella spp. foi maior quando comparada com outras pesquisas realizadas no Brasil, como as realizadas por Cardoso et al. (2015) e Borsoi et al. (2010), os quais isolaram o patógeno em $14,6 \%$ e $12,2 \%$ das carcaças de frango, respectivamente. Cardoso et al. (2000) não identificaram Salmonella em 20 amostras de frangos inteiros avaliadas, bem como em amostras de coxa, sobrecoxa, peito, linguiça e salsicha de frango provenientes de frigoríficos do estado de São Paulo, em adição, também, não foram detectados coliformes termotolerantes. Do mesmo modo, bactérias do gênero Salmonella e do grupo coliformes termotolerantes não foram detectadas em 24 amostras de carcaças comercializadas na cidade de Recife (Pires et al., 2009). Fato que traz a preocupação em relação aos resultados apresentados (Tabela 1). Quanto à presença de estafilococos, Freitas et al. (2004a) identificaram S. aureus em $65 \%$ das carcaças analisadas, as quais foram coletadas em mercados públicos e supermercados. Neste caso, a falta do controle de temperatura de armazenamento nos nestes estabelecimentos teve importância para a obtenção dos resultados, sendo a frequência detectada significativamente superior à apresentada no presente trabalho. 
Associada a preocupação com a presença de patógenos alimentares está a resistência a antibióticos dos mesmos. A resistência a diferentes antibióticos foi avaliada para todos os 46 isolados confirmados por testes bioquímicos. A susceptibilidade a todos os antibióticos testados foi encontrada em $9,1 \%, 33,3 \%$ e $33,3 \%$ dos isolados de E. coli, Salmonella spp. e S. aureus, respectivamente. Dos 46 isolados, apenas $4,3 \%$ (2 isolados de S. aureus, representando $11,1 \%$ das cepas da respectiva espécie) apresentaram somente resistência intermediária, a qual foi identificada para tetraciclina. A resistência a um ou mais antibióticos foi detectada em $90,9 \%, 66,6 \%$ e $55,6 \%$ dos isolados de E. coli, Salmonella spp. e S. aureus, respectivamente. Diferentes perfis de resistência foram identificados para os isolados analisados (Tabela 2), portanto, a diversidade dos perfis de resistência e principalmente a multirresistência dos isolados são destacados. Patógenos alimentares resistentes, incluindo Campylobacter, Salmonella Typhi, salmonellae nãotifoidal e Shigella, são considerados ameaças graves pelo Centro de Controle e Prevenção de Doenças dos Estados Unidos (Doyle, 2015).

Infecções causadas por bactérias multirresistentes podem aumentar a morbidade, a mortalidade e o uso de antibióticos caros e hospitalizações prolongadas. Humanos podem estar expostos a bactérias resistentes a antibióticos através do ambiente, locais de cuidados com a saúde, fazendas, alimentos e por outros indivíduos portadores das bactérias em questão (Doyle, 2015). Cepas multirresistentes têm sido detectadas em carnes

Tabela 1 - Dados obtidos no isolamento de Escherichia coli, Salmonella spp. e Staphylococcus aureus

\begin{tabular}{lccc}
\hline Patógeno pesquisado & Colônias típicas(n) & Colônias confirmadas (n, \%) & Carcaças positivas(n, \%) \\
\hline E.coli & 28 & $22,78,6$ & 14,70 \\
Salmonella spp. & 39 & $6,15,4$ & 5,25 \\
S. aureus & 33 & $18,54,5$ & 8,40 \\
\hline
\end{tabular}

Tabela 2 - Resistência a antibióticos identificada em Escherichia coli, Salmonella spp. e Staphylococcus aureus isolados de carcaças de frango

\begin{tabular}{ll}
\hline Isolado & Perfil de resistência a antibiótico* (n) \\
\hline E. coli & amp, amo, tet (1) \\
& amp, azt, gen tob, tet (1) \\
& amp, azt, tet (1) \\
& amp. Azt, tet, clo (2) \\
& amp, cef, clo (1) \\
& amp,cef, gen (1) \\
& amp, gen, tet (2) \\
& amp, tet (4) \\
amp, tet, clo (2) \\
amp, tob, tet (1) \\
cef, azt, tet, clo (1) \\
tet (3) amp, amo, tet (1) \\
almonella spp. \\
amp, tet (1) \\
amp, amo, cef (1) \\
amp, cef (1) \\
oxa (3) \\
oxa, tob, eri (1) \\
pen, oxa, cli (1) \\
pen, oxa, cli (1) \\
pen, oxa, eri, cli (4)
\end{tabular}

* amp= ampicilina; amo = amoxilicina-ácido clavulânico; cef = cefoxitina; azt = aztreonam; gen = gentamicina; tob = tobramicina, tet =tetraciclina; clo $=$ cloranfenicol; oxa $=$ oxacilina; pen = penicilina; eri $=$ eritromicina; $c l i=$ clindamicina . 
e produtos frescos. Em carnes, a presença de cepas multirresistentes pode ter originado dos ambientes veterinários ou nas fazendas através do uso de antibióticos na alimentação dos animais ou no tratamento de infecções, além disso, manipuladores de alimentos, fazendeiros e cuidadores de animais também devem ser considerados como possíveis fontes de contaminação (Doyle, 2015).

A resistência a agentes antimicrobianos de cepas de E. coli isoladas de amostras de animais foi detectada como crescente em estudo que elaborou uma retrospectiva de pesquisas de 1950 a 2002, incluindo a ampicilina e gentamicina (Tadesse et al., 2012). Entre os antibióticos avaliados, a resistência a ampicilina foi a segunda mais frequente entre E. coli (Tabela 2). Tadesse et al. (2012) identificaram que a co-resistência mais frequente entre $E$. coli incluía tetraciclina (estroptomicina e tetracilina, 29,7\%) (Tadesse et al. 2012), antibiótico mais observado nos perfis de resistente de E. coli aqui descritos. Para a mesma espécie observouse a presença de isolados resistentes a cloranfenicol, sendo seu uso proibido em animais produtores de alimentos no Brasil (Brasil, 2003b), o não uso do cloranfenicol é indicado pelo Codex Alimentarius (FAO, 2017).

Para Salmonella, foram identificados quatro isolados resistentes, sendo os mesmos resistentes a ampicilina. Quanto a resistência a cefoxitina, tetraciclina e amoxicilina observou-se a mesma frequência (Tabela 2), sendo assim $66,6 \%$ dos isolados apresentaram resistência a dois ou mais antibióticos. Por outro lado, Medeiros et al. (2011) ao investigar a resistência a 18 antibióticos de Salmonella spp. isoladas de carcaças de frango congelado obtidas em capitais brasileiras identificaram resistência a um ou mais antibióticos em $100 \%$ das cepas (250 cepas). Contudo, na mesma pesquisa, destacou-se a baixa prevalência do patógeno nas 679 amostras de frango, $2,7 \%$, sendo que mais de $50 \%$ das amostras positivas foram identificadas em São Paulo (Medeiros et al., 2011). Ressalta-se que as amostras utilizadas no presente trabalho foram adquiridas no interior do Estado de São Paulo.

Já a resistência a diferentes antibióticos por $S$. aureus tem sido comumente encontrada em amostras de frango comercializadas no Brasil (Freitas et al., 2001; Freitas et al., 2004b) e em alimentos de origem animal (Kuchenbecker et al., 2009), em geral. Entretanto, vale ressaltar que $100 \%$ dos isolados resistentes aqui descritos apresentaram resistência a oxacilina. A resistência a oxacilina historicamente é utilizada para a detecção de Staphylococcus aureus resistentes a meticilina (Methicillin-Resistant Staphylococcus aureus, MRSA), mas sabe-se atualmente que a cefoxitina é um indutor melhor do gene mecA, e testes usando cefoxitina apresentam melhor reprodutibilidade e acurácia comparados com testes com oxacilina (CDC, 2017). Como os resultados não apontaram a resistência a cefoxitina, métodos moleculares são necessários para a identificação precisa de cepas MRSA.

Compreendendo a importância de tais cepas e o aumento e a disseminação de cepas resistentes a antibióticos atuais outros antimicrobianos vêm sendo pesquisados. Há o uso potencial de substâncias bioativas derivadas de plantas (Bajpai; Baeg; Kang, 2012), desse modo, a CIM de óleos essenciais foi investigada empregando os isolados obtidos. Verificou-se melhor atividade antimicrobiana em óleo essencial de Cymbopogon citratus e Rosmarinus officinalis, os quais não diferiram significativamente entre si para os micro-organismos analisados (Tabela 3), e foram identificadas baixas concentrações dos Oes para a inibição do crescimento bacteriano.

O óleo essencial de Piper nigrum demonstrou não ser um bom inibidor comparado aos demais Oes, principalmente para bactérias Gram negativas, E. coli e Salmonella spp., devido a alta concentração para inibição do crescimento bacteriano. García-Díez et al. (2016) mencionam que a utilização de Oes em alimentos visando a segurança alimentar é uma importante estratégia, mas a alta concentração é um fator sensorial limitante. A CIM descrita é similar a encontrada para $\mathrm{OE}$ de alecrim no trabalho de Barbosa et al. (2016), neste houve atividade inibitória na concentração de $5 \mu \mathrm{L} / \mathrm{mL}$ contra $L$. monocytogenes e E. coli, entretanto, foi reportado $10 \mu \mathrm{L} / \mathrm{mL}$ contra S. enteritidis. Os dados apresentados mostram também que as menores concentrações necessárias para a inibição do crescimento de patógenos foi identificada para capim-limão, em consonância com pesquisa previamente desenvolvida em que diversos patógenos foram testados e o óleo de capim-limão foi efetivo, sendo que bactérias Gram positivas foram mais susceptíveis do que Gram negativas (Naiak et al., 2010). Segundo o estudo conduzido por Naiak et al. (2010), há indicação de que Gram negativas com alta resistência 
a diferentes antibióticos foram inibidas por óleo de capim-limão em menores concentrações, o óleo foi efetivo contra cepas resistentes e pode ser sugerido para tratamento de infecções causadas por cepas multirresistentes. Porém, ao testar CBM (Tabela 4), observou-se que $\mathrm{OE}$ de capim-limão foi bactericida apenas para isolados de Salmonella. Quanto ao OE de pimenta preta, testes futuros podem ser realizados, por exemplo, com extratos etanólicos e metanólicos a fim de alcançar melhores resultados como mostrados por Akthar et al. (2014).

Adicionalmente, os resultados da análise da CBM (Tabela 4) indicam que o óleo essencial de pimenta apresentou pouco efeito bactericida a partir da CIM testada, enquanto o óleo essencial de alecrim teve efeito considerável, por exemplo, para a cepa SA16. Já para óleo de capim-limão verificou-se a CIM e predominante ação bacteriostática. Já os isolados de E. coli foram resistentes, havendo crescimento em todos os ensaios (Tabela 4), resultado que traz preocupação, uma vez que isolados da espécie foram resistentes a antibióticos; somando fatores, pode-se sugerir o potencial de sobrevivência e disseminação de material genético de importância.

\section{CONCLUSÕES}

A alta frequência de amostras de frango positivas para os patógenos alimentares investigados ressalta a necessidade de maiores cuidados na produção, transporte e armazenamento. Adicionalmente, a alta prevalência de isolados multirresistentes a antibióticos reforça a preocupação atual com a disseminação de bactérias resistentes na cadeia produtiva de alimentos. Isolados obtidos foram avaliados quanto à resistência frente a óleos essenciais. Os Oes de alecrim e capimlimão destacam-se pelos resultados apresentados neste trabalho. Entretanto, sugere-se para trabalhos futuros o uso de diferentes derivados de alecrim, capim-limão e pimenta preta frente à patógenos a fim de comparar os diversos resultados e assim sugerir aplicações para a indústria de alimentos.

\section{AGRADECIMENTOS}

Agradecemos às agências de fomento que tornaram possível a realização deste estudo: Conselho Nacional de Pesquisa (CNPQ), Coordenação de Aperfeiçoamento de Pessoal de Nível Superior (CAPES), Fundo de Apoio ao Ensino, à Pesquisa e Extensão (FAEPEX) e PróReitoria de Pesquisa da Unicamp (PRP).

Tabela 3 - Concentração Inibitória Mínima (CIM) de óleos essenciais expressa em mg/mL

\begin{tabular}{lccc}
\hline Isolados & $\begin{array}{c}\text { Capim-Limão } \\
\text { Cymbopogon citratus) }\end{array}$ & $\begin{array}{c}\text { Pimenta-Preta } \\
\text { (Piper nigrum) }\end{array}$ & $\begin{array}{c}\text { Alecrim } \\
\text { (Rosmarinus officinalis) }\end{array}$ \\
\hline E. coli & $1,19 \pm 0,39^{\mathrm{a}}$ & $65,55 \pm 26,76^{\mathrm{b}}$ & $4,39 \pm 1,49^{\mathrm{a}}$ \\
Salmonella spp. & $3,08 \pm 1,93^{\mathrm{a}}$ & $70,4 \pm 26,26^{\mathrm{b}}$ & $3,29 \pm 1,41^{\mathrm{a}}$ \\
S. aureus & $0,43 \pm 0,43^{\mathrm{a}}$ & $17,00 \pm 16,88^{\mathrm{b}}$ & $2,27 \pm 1,60^{\mathrm{a}}$ \\
\hline
\end{tabular}

Letras diferentes nas linhas indicam médias que diferem estatisticamente, a $5 \%$ de probabilidade, pelo teste de Tukey.

Tabela 4 - Concentração Bactericida Mínima (CBM) de óleos essenciais expressa em \%

\begin{tabular}{|c|c|c|c|c|c|c|c|c|c|}
\hline \multirow{2}{*}{$\begin{array}{l}\text { Isolados } \\
\text { EC1 }\end{array}$} & \multicolumn{3}{|c|}{ Capim-Limão(Cymbopogon citratus) } & \multicolumn{3}{|c|}{ Pimenta-Preta(Piper nigrum) } & \multicolumn{3}{|c|}{ Alecrim(Rosmarinus officinalis) } \\
\hline & + & + & + & + & + & + & + & + & + \\
\hline $\mathrm{EC} 2$ & + & + & + & + & + & + & + & + & + \\
\hline EC5 & + & + & + & + & + & + & + & + & + \\
\hline SAL6 & 0,312 & 1,25 & 0,156 & + & + & + & + & 0,625 & 0,312 \\
\hline SAL17 & + & + & + & + & + & + & + & 0,625 & + \\
\hline SAL20 & + & + & 0,312 & + & + & + & + & 0,312 & 0,312 \\
\hline SA12 & + & + & + & + & + & + & 2,5 & 5,0 & + \\
\hline SA 16 & + & + & + & 0,625 & 0,312 & + & 0,156 & 0,312 & 0,156 \\
\hline SA 18 & + & + & + & 10 & + & + & 0,312 & 0,312 & 0,156 \\
\hline
\end{tabular}

$\mathrm{EC}=$ Escherichia coli $; \mathrm{SAL}=$ Salmonella $; \mathrm{SA}=$ Staphylococcus aureus $;+=$ não houve efeito bactericida na CIM nem nas três concentrações anteriores; valores apresentam a menor concentração (\%) com atividade bactericida. 


\section{LITERATURACITADA}

AKTHAR, M.S.; BIRHANU, G.; DEMISSE, S. Antimicrobial activity of Piper nigrum L. and Cassia didymobotyra L. leaf extract on selected food borne pathogens. Asian Pacific Journal of Tropical Disease, v.4, suppl. 2, p.S911-S919, 2014.

BAJPAI, V.K.; BAEK, K.H.; KANG, S.C. Control of Salmonella in foods by using essential oils: A review. Food Research International, v.45, n.2, p.722-734, 2012.

BARBOSA, I.M.; MEDEIROS, J.A.C.; OLIVEIRA, K.A.R. et al. Efficacy of the combined application of oregano and rosemary essential oils for the control of Escherichia coli, Listeria monocytogenes and Salmonella Enteritidis in leafy vegetables. Food Control, v.59, p.468-477, 2016.

BASSANETTI, I.; CARCELLI, M.; BUSCHINI, A. et al. Investigation of antibacterial activity of new classes of essential oils derivatives. Food Control, v.73, part B, p.606-612, 2017.

BORSOI, A.; MORAES, H.L.S.; SALLE, C.T.P. et al. Número mais provável de Salmonella isoladas de carcaças de frango resfriadas. Ciência Rural, v.40, n.11, p.2338-2343, 2010 .

BRASIL. Instrução Normativa ${ }^{\circ} 62$, de 26 de agosto de 2003 - Ministério da Agricultura, Pecuária e Abastecimento. 2017. In: www.a3q.com.br/dmdocuments/Instru_Normativa 62.pdf (acessado em 11 de setembro de 2017)a.

BRASIL. Instrução Normativa ${ }^{\circ} 9$, de 27 de junho de 2003 - Ministério da Agricultura, Pecuária e Abastecimento. 2017. In: http:// sistemasweb.agricultura.gov.br/sislegis/action/ detalhaAto.do?method=visualizarAtoPotalMapa\&chave $=2112258128$ (acessado em 11 de setembro de 2017)b.

CARDOSO,A.L.S.P.; TESSARI, E.C.N.; CASTRO,A.GM. et al. Pesquisa de Salmonella spp., coliformes totais, coliformes fecais e mesófilos em carcaças e produtos derivados de frango. Arquivos do Instituto Biológico, v.67, n.1, p.25-30, 2000.

CARDOSO, A.L.S.P.; KANASHIRO, A.M.I.; STOPPA, G.F.Z. et al. Ocorrência de Salmonella spp. em carcaças de frango provenientes de abatedouros do estado de São Paulo, Brasil, no período de 2000 a 2010. Revista Científica de Medicina Veterinária, n.24, p.1-12, 2015.
CDC - Centers of Disease Control and Prevention. Methicillin-resistant Staphylococcus aureus (MRSA). 2017. In: https://www.cdc.gov/mrsa/ lab/index.html (acessado em 12 de setembro de 2017).

CLEMENTE, I.;AZNAR, M.; SILVA, F. etal.Antimicrobial properties and mode of action of mustard and cinnamon essential oils and their combination against foodborne bacteria. Innovative Food Science \& Emerging Technologies, v.36, p.26-33, 2016.

CLSI. M02-A12: Performance Standards for Antimicrobial Disk Susceptibility Tests; Approved Standard - Twelfth Edition, 2015.

DANNENBERG, G.S.; FUNCK, G.D.; CRUXEN, C.E.S. et al. Essential oil from pink pepper as an antimicrobial component in cellulose acetate film: Potential for application as active packaging for sliced cheese. LWT - Food Science and Technology, v.81, p.314$318,2017$.

DOYLE, M.E. Multidrug-resistant pathogens in the food supply. Foodborne Pathogens and Disease, v.12, n.4, p.261-279, 2015.

FERREIRA, Daniel Furtado. Sisvar: a Guide for its Bootstrap procedures in multiple comparisons. Ciência e Agrotecnologia [online]. 2014, v.38, n.2 [citado 2015-10-17], p.109-112. Disponible en: ISSN 1413-7054. http://dx.doi.org/10.1590/S1413-70542014000200001.

FREITAS, M.F.L.; MOTA, R.A.; VILELA, S.M. et al. Cepas se Staphylococcus spp. isoladas de carcaças de frango comercializadas na cidade do Recife - PE, Brasil. Ciência Animal Brasileira, v.2, n.2, p.139-145, 2001.

FREITAS, M.F.L.; LEÃO, A.E.D.S.; STAMFORD, T.L.M. et al. Ocorrência de Staphylococcus aureus em carcaças de frango. B. CEPPA, v.22, n.2, p.271-282, 2004a.

FREITAS, M.F.L.; MOTA, R.A.; LEÃO, A.E.D.S. et al. Sensibilidade antimicrobiana de cepas de Staphylococcus spp. isoladas de carcaças de frango comercializadas em Recife. Arquivo Brasileiro de Medicina Veterinária e Zootecnia, v.56, n.3, p.405-407, 2004b.

GARCÍA-DÍEZ, J.; ALHEIRO, J.; PINTO, A.L. et al. Behaviour of food-borne pathogens on dry cured sausage manufactured with herbs and spices essential oils and their sensorial acceptability. Food Control, v.29, p.262$270,2016$. 
GEBREYES, W.A.; WITTUM, T.; HABING G etal. Spread of Antibiotic Resistance in Food Animal Production Systems. In: DODD, C.; ALDSWORTH, T.; STEIN, R.A. et al. (Ed.). Foodborne Diseases (Third edition). Cambridge: Academic Press, 2017. p.105-130.

HINTZ, T.; MATTHEWS, K.K.; RONG, D. The Use of Plant Antimicrobial Compounds for Food Preservation. BioMed Research International, p.1-12, 2015.

JONG, A.; SMET, A.; LUDWIG, C. et al. Antimicrobial susceptibility of Salmonella isolates from healthy pigs and chickens (2008-2011). Veterinary Microbiology, v.171, p.298-306, 2014.

KNEZEVIC, P.;ALEKSIC, V.; SIMIN, N. etal. Antimicrobial activity of Eucalyptus camaldulensis essential oils and their interactions with conventional antimicrobial agents against multi-drug resistant Acinetobacter baumannii. Journal

Of Ethnopharmacology, [s.1.], v.178, p.125-136, 2016.

KUCHENBECKER, B.S.; RIBEIRO, A.R.; CARDOSO, M. Perfil de resistência de isolados de Staphylococcus aureus obtidos de produtos de origem animal analisados pelo Serviço de Inspeção Federal do Brasil. Acta Scientiae Veterinariae, v.37, n.2, p.143-149, 2009.

MEDEIROS, A.N.; OLIVEIRA, D.C.N.; RODRIGUES, D.P. et al. Prevalence and antimicrobial resistance of Salmonella in chicken carcasses at retail in 15 Brazilian cities. Revista Panamericana de Salud Pública, v.30, n.6, p.555-560, 2011.

MINISTÉRIO DA SAÚDE. Surtos de doenças transmitidas por alimentos no Brasil. 2016. In: http://portalarquivos.saude.gov.br/images/pdf/2016/ junho/08/Apresenta- - o-Surtos-DTA-2016.pdf (acessado em 02 de setembro de 2017).
PERAZZO, M.F.; COSTANETA, M.C.C.; CAVALCANTI, Y.W. et al. Efeito antimicrobiano do óleo essencial do Cymbopogon citratus sobre bactérias formadoras do biofilme dentário. Revista Brasileira de Ciências da Saúde, [s.1.], v.16, n.4, p.553-558, 2012.

PESAVENTO, G.; CALONICO, C.; BILIA, A.R. et al. Antibacterial activity of Oregano, Rosmarinus and Thymus essential oils against Staphylococcus aureus and Listeria monocytogenes in beef meatballs. Food Control, v.54, p.188-199, 2015.

PIRES, D.S.L.; PACHECO, M.S.; ROLIM, M.B.Q. et al. Pesquisa de Salmonella spp. e coliformes termotolerantes em carcaças de frangos in natura comercializados no Distrito Sanitário V da Cidade do Recife - PE. Medicina Veterinária, v.3, n.1, p.31-36, 2009.

SILVA, N.; JUNQUEIRA, V.C.A.; SILVEIRA, N.F.A. et al. Manual de métodos de análise microbiológica de alimentos e água. $4^{\mathrm{a}}$ ed. São Paulo: Blucher, 2010.

SETTANI, L.; PALAZZOLO, E.; GUARRASI, V. et al. Inhibition of foodborne pathogen bacteria by essential oils extracted from citrus fruits cultivated in Sicily. Food Control, v.26, n.2, p.326-330, 2012.

WANG, X.; TAO, X.; XIA, X. et al. Staphylococcus aureus and methicillin-resistant Staphylococcus aureus in retail raw chicken in China. Food Control, v.29, p.103-106, 2013.

YAP, P.S.X.; YIAP, B.C.; PING, H.C. Essential oils, a new horizon in combating bacterial antibiotic resistance. The Open Microbiology Journal, v.8, p.6-14, 2014.

ZHANG, S.; WU, Q.; ZHANG, J. et al. Prevalence, genetic diversity, and antibiotic resistance of enterotoxigenic Escherichia coli in retail ready-to-eat foods in China. Food Control, v.68, p.236-243, 2016.

Recebido para publicação em 23/12/2017 e aprovado em 23/3/2018. 